Sportfunktionäre und jüdische Differenz 



\section{Sportfunktionäre und jüdische Differenz}

Zwischen Anerkennung und Antisemitismus Wien 1918 bis 1938

Herausgegeben von Bernhard Hachleitner, Matthias Marschik und Georg Spitaler

\section{DE GRUYTER \\ OLDENBOURG}


Veröffentlicht mit Unterstützung des Austrian Science Fund (FWF):

Projekt PUB 584-Z28

Der Wissenschaftsfonds.

ISBN 978-3-11-055326-0

e-ISBN (PDF) 978-3-11-055331-4

e-ISBN (EPUB) 978-3-11-055344-4

\section{(cc) BY}

Dieses Werk ist lizenziert unter der Creative Commons Attribution 4.0

International Lizenz (CC BY 4.0).

Weitere Informationen finden Sie unter https://creativecommons.org/licenses/by/4.0/.

\section{Library of Congress Publication Number: 2018956660}

\section{Bibliografische Information der Deutschen Nationalbibliothek}

Die Deutsche Nationalbibliothek verzeichnet diese Publikation in der Deutschen Nationalbibliografie; detaillierte bibliografische Daten sind im Internet über http://dnb.dnb.de abrufbar.

(C) 2019 Bernhard Hachleitner, Matthias Marschik und Georg Spitaler, publiziert von Walter de Gruyter GmbH, Berlin/Boston

Dieses Buch ist als Open-Access-Publikation verfügbar über www.degruyter.com, https://www.doabooks.org und https://www.oapen.org

Bildnachweis: Austria-Präsident Dr. Emanuel Schwarz am Spielfeldrand des Wiener Praterstadions beim Mitropacupspiel gegen Juventus Turin, 9. 7. 1933 (Privatarchiv Thomas Schwarz)

Satz: Meta Systems Publishing \& Printservices GmbH, Wustermark

Druck und Bindung: CPI Books GmbH, Leck

www.degruyter.com 